Rechtsmedizin 2016 $26: 485-488$ DOI 10.1007/s00194-016-0121-2 Published online: 21 October 2016 (C) The Author(s) 2016. This article is available at SpringerLink with Open Access.

CrossMark
W. Hitzl' $\cdot$ T. Keller ${ }^{2} \cdot$ F. Monticelli ${ }^{2}$

${ }^{1}$ Research Office, Biostatistics, Paracelsus Medical University, Salzburg, Austria

${ }^{2}$ IFFB Gerichtsmedizin \& Forensische Neuropsychiatrie, Paris Lodron Universität Salzburg, Salzburg, Austria

\title{
in routine police traffic checks
}

\begin{abstract}
In order to evaluate the fitness to drive of each traffic participant, standardized and objective measurement methods, such as infrared pupillography are needed. We present a statistical analysis of pupillographic data that could provide the basis for a tool to identify drivers who warrant further clinical examination, including blood testing.
\end{abstract}

\section{Background}

The applicability and value of infrared pupillography as an objective measurement method to indicate the possible influence of substances acting on the central nervous system (CNS) has been demonstrated in previous publications [1-3]. In particular, these studies successfully identified various pupil function parameters, which significantly differ between healthy subjects and persons participating in a drug substitution program. From a methodological perspective these results are important because they show that various pupil function parameters possess discriminatory powers; however, for practical purposes it is necessary to find out whether a subject is under the influence of a substance acting on the CNS. For example, during a routine traffic control it is highly desirable to identify such subjects in order to substantially improve road safety. Hence, the following questions still remain open: what is the extent of this discriminatory power and do pupil function parameters have enough discriminatory power to allow identification on an individual level? Identification of individual subjects is, however, much more difficult to achieve and it is a priori not clear whether a statistical model exists with sufficient discriminatory power. The objective of this study was to search for possible candidate models and to evaluate their performances in this setting.

\section{Material and methods}

\section{Pupillography}

A detailed description of this study is given in $[1,2]$. As reported we exposed the iris of healthy test subjects, as well as of persons who were under the influence of drugs or medication, to different light stimuli using infrared technology in order to obtain information about the neurological status. Some of them were tested more than once and were therefore excluded from the present statistical analysis. The measurements were taken using the standard, heightadjustable free-standing version of the Compact Integrated Pupillograph (CIP, AMTech, Dossenheim, Germany). The CIP measures the horizontal pupil diameter using a CCD infrared line scan camera and a video camera and determines the diameter of the pupil with a resolution of $0.01 \mathrm{~mm}$ on the basis of the different reflex reactions of the iris and pupil using a measuring frequency of $250 \mathrm{~Hz}$ over a period of $2 \mathrm{~s}$. In this process, the pupil is continuously and diffusely illuminated with two infrared diodes. The duration of the stimulus can be varied between 0.1 and $0.2 \mathrm{~s}$. The brightness of the stimulus can also be freely selected between 254 and 1 . The light intensity values were randomly selected by AMTech and have no unit of measurement an range between approximately 0.22 and 56 lux (measured at the vertex of the cornea). With the CIP it was also possible to achieve a diameter-dependent adaptation of the light reflex so that the amount of light hitting the retina in a series of measurements could be kept constant while taking the diameter of the pupil into account. This measurement mode is referred to as the $\mathrm{PLR}+$ mode. Once the measurement has been taken, pupil movement is shown in graphic form on the connected laptop. At the same time special software breaks down the pupil reaction into various parameters according to predetermined measurement points and intervals. On the monitor the tester gains first impressions of the pupil and its ability to react and can also read off the parameters calculated in the respective window.

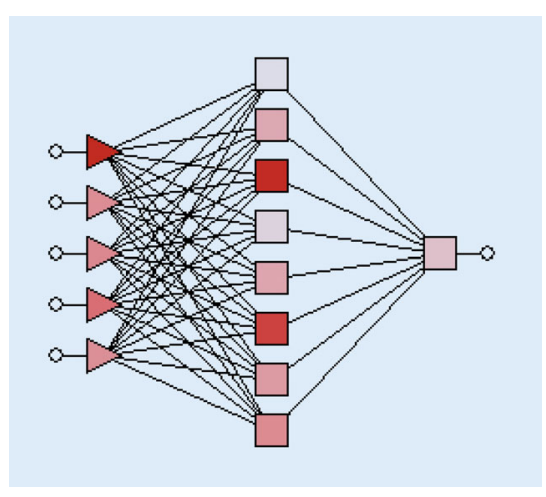

Fig. 1 \& Illustration of the 3-layer perceptron neural network with 5 input variables: sex, contraction velocity, latency, reaction time and relative amplitude 
Rechtsmedizin 2016 -26:485-488 DOI 10.1007/s00194-016-0121-2

(c) The Author(s) 2016. This article is available at SpringerLink with Open Access.

\author{
W. Hitzl · T. Keller · F. Monticelli
}

\title{
Infrared pupillography in routine police traffic checks. Analysis of potential applications based on advanced statistical models
}

\section{Abstract}

Background. In order to evaluate the ability of traffic participants to drive, standardized and objective measurement methods are needed. In recent analyses it was shown that pupil function is a significant indicator of being under the influence of substances acting on the central nervous system.

Objective. The aim of this study was to answer the question whether it is possible to detect if a person is under the influence of drugs or medication based on pupil function.

Material and methods. In total 121 subjects were exposed to different light stimuli and an infrared pupillographic investigation of the eyes was carried out. The study cohort consisted of 41 healthy test subjects and 80 subjects under the influence of drugs or medication. Several neural network models with different network architectures were trained in a learning group, further analyzed in a verification sample and most importantly tested in an independent test sample. Specificity, sensitivity, negative and positive predictive values as well as the percentage of correctly predicted subjects were analyzed. A $95 \%$ confidence interval $(\mathrm{Cl})$ was included for all performance measurements.

Results. A neural network model was found which performed with a specificity of $91 \%$ $(95 \% \mathrm{Cl}, 78-98 \%)$, sensitivity $90 \%(95 \% \mathrm{Cl}$,
$81-96 \%)$, negative predictive value $85 \%$ (95\% $\mathrm{Cl}, 72-94 \%)$, positive predictive value $94 \%$ (95\% Cl, 86-98\%) and a correct prediction was made for $90 \%(95 \% \mathrm{Cl}, 83-95 \%)$ of the subjects.

Conclusion. The results of this study clearly show that infrared pupillography provides excellent discrimination between healthy subjects and persons under the influence of drugs or medication in this specific setting.

Keywords

Infrared pupillography - Traffic medicine . Neural network · Fitness to drive $\cdot$ Drugs

\section{Infrarot-Pupillographie im Rahmen polizeilicher Routineverkehrskontrollen. Analyse der Anwendungsmöglichkeiten basierend auf modernen statistischen Modellen}

\section{Zusammenfassung}

Hintergrund. Um die Fahrtüchtigkeit eines Teilnehmers am Straßenverkehr zu evaluieren, sind objektive und standardisierte Messmethoden notwendig. In rezenten Studien konnte nachgewiesen werden, dass die Pupillenfunktion als signifikanter Indikator zur Beurteilung des Einflusses durch zentralnervös wirksame Substanzen herangezogen werden kann.

Ziel der Arbeit. Ziel dieser Studie ist die Beantwortung der naheliegenden Frage: „Ist es - basierend auf der Pupillenfunktion - möglich zu ermitteln, ob eine bestimmte Person unter der Wirkung von Drogen oder Medikamenten steht oder nicht?"

Material und Methoden. Insgesamt wurden 121 Probanden einer infrarot-pupillographischen Untersuchung des Auges unter Verwendung unterschiedlicher Lichtreize unterzogen. Dabei wurden einerseits 41 gesunde, nicht beeinträchtigte, andererseits 80 Probanden untersucht, welche nachweislich unter dem Einfluss von Drogen oder Medikamenten standen. Neuronale Netze mit unterschiedlicher Netzwerkarchitektur wurden in einer Lerngruppe trainiert, danach in einer Verifikationsstichprobe weiter analysiert und in einer unabhängigen Teststichprobe abschließend getestet. Spezifität, Sensitivität, der negative und positive prädiktive Wert als auch der prozentuale Anteil der insgesamt als korrekt eingestuften Probanden wurden ermittelt. Für sämtliche Performancewerte wurden $95 \%$-Konfidenzintervalle (CI) angegeben.

Ergebnisse. Ein neuronales Netzwerk mit folgenden Werten konnte ermittelt werden: Spezifität (91 \%, 95\% Cl 78-98 \%), Sensitivität
(90\%, $95 \%$ Cl 81-96\%), negativer prädiktiver Wert (85\%, $95 \% \mathrm{Cl} 72-94 \%)$ und positiver prädiktiver Wert (94\%, $95 \% \mathrm{Cl} 86-98 \%)$; $90 \%$ (95\% Cl 83-95\%) aller Personen wurden korrekt eingeschätzt.

Schlussfolgerung. Die Ergebnisse dieser Studie zeigen eindeutig, dass es mittels Infrarot-Pupillographie - zumindest in diesem speziellen Studiensetting - möglich ist, Personen, die unter dem Einfluss von Drogen oder Medikamente stehen, klar zu identifizieren.

Schlüsselwörter Infrarot-Pupillographie - Verkehrsmedizin . Neurales Netzwerk · Fahrtüchtigkeit· Drogen

\section{Statistical methods}

We chose two approaches for the statistical evaluation of the data. In a first approach we analyzed sex, contraction velocity, latency, reaction time and relative amplitude using different previously standardized light stimuli. In order to obtain a higher comparability between affected (i.e. those who are under drugs or medications) and non-affected subjects (control group with normal subjects not under influence of drugs) a second approach was used by analyzing the same parameters keeping the amount of the light hitting the retina constant by calculating the stimulus intensity in relation to the initial pupil diameter of the subject. In order to meet the statistical assumptions for modelling, repetitive measurements were not included in the study; therefore, the sample size differs from the previous publications $(n=121)$.
Various neural network models including linear networks, networks with radial basis functions and 3-layer perceptron networks were trained and tested. All networks were scaled using the minimax method and trained with a back-propagation algorithm. A variable search algorithm was applied to identify a set of input variables with high discrimination power [4]. The sample of 121 subjects was split into 3 subsamples consisting of a training, verification and 


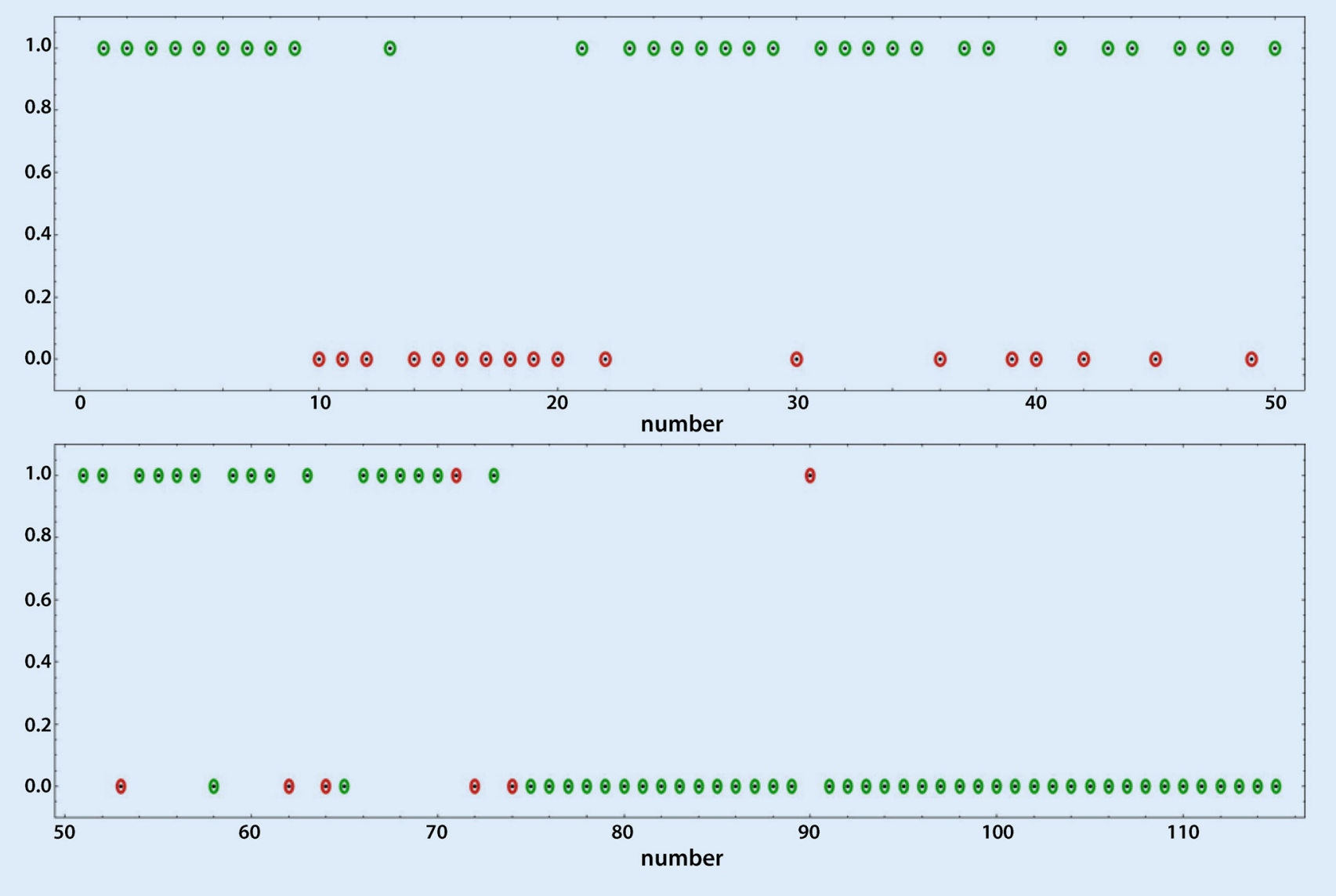

Fig. $2 \Delta$ Illustration of the performance of the neural network model: Green outlined dotsillustrate correctly identified subjects and red outlined dots correspond to false identifications

independent test sample with random numbers in the ratio $2: 1: 1$, respectively based on computer generated random numbers. Sensitivity, specificity, negative and positive predictive values as well as the percentage of correctly predicted subjects were computed together with $95 \%$ confidence intervals. All analyses were carried out using STATISTICA 13 [5], STATISTICA neural network [6] and MATHEMATICA 7 [7].

\section{Results}

A total of 50 neural networks with different network architectures were trained and ultimately two 3-layer perceptron networks were identified with excellent performances. The first model (• Fig. 1) used a cut-off value of $85.6 \%$ and performed as follows: specificity (91\%, $95 \%$ CI $78-98 \%$ ), sensitivity (90\%, $95 \%$ CI $81-96 \%)$, negative predictive value ( $85 \%$, $95 \%$ CI $72-94 \%$ ), positive predictive value (94\%, $95 \%$ CI 86-98 \%) and $90 \%$ (83-95\%) of subjects were correctly predicted. An illustration of the performance of the model is given in - Fig. 2. The performance of the second approach was almost identical to those of the first approach.

\section{Discussion}

The results of this analysis clearly identified a neural network model with high predictive power to allow identification of subjects under the influence of substances acting on the CNS. It is well known in the statistical literature [4] that it is easily possible to find statistical models which perform well in a training sample but entirely fail when the model is applied and tested in a new test sample. This is a very important phenomenon, so called over-generalization, which can only be handled by using a proper training, verification and test sample whereby all three samples have to be randomly selected [4]. This has been carefully done in this study and therefore the study is ultimatelybased on a statistically sound model.

Due to differing standards it is necessary to advise caution when comparing scientific studies. In fact, it is known that the extent of pupil contraction (amplitude) depends on the intensity of retinal stimulation. In pupillographic research, for example, the results from Kristek et al. suggested that the differing extent of pupillary contraction was due to the changing influence of the light stimulus on the various initial pupil diameters [8]. This problem was avoided in this study by testing the pupillary light reflex in the so-called PLR+ mode with a light intensity that was adapted to the initial pupillary diameter. From this it may be inferred that the amplitude of the reaction to light is a function of the initial pupil diameter because with smaller pupils less light enters the eye and hence 
strikes the retina. This phenomenon renders the interpretation of pupillary light reactions with various initial diameters under otherwise identical test conditions more difficult. This basic experimental problem has been ignored in most of the pupillographic studies published to date, as it was partially irrelevant for the aim of the respective studies.

One of the strengths of this study is that it is the first study which used modern statistical models to identify subjects under the influence of substances acting on the CNS. These models permit generalizations to new subjects because all statistical models were analyzed and compared in all three samples and most importantly tested in an independent test sample; therefore, the model does not suffer from over-learning.

We achieved very high sensitivity, specificity, negative and positive predictive values and more than $90 \%$ of all subjects were correctly classified. On the other hand, it has to be stated that the statistical mode is relevant only in this specific setting of the study. Due to comparatively high levels of medication in the substitution group by more than one substance, the differentiation of a specific substance may not yet be possible, particularly because different substances taken at the same time in several cases could develop reciprocal actions. The performance of the statistical models based on measurements in the PLR+ mode could not enhance the statistical accuracy as expected, which may be important for respective studies in the future.

Further studies are necessary to obtain more detailed information about the specific effects of individual substances. First pupillographic examinations of persons under the influence of tetrahydrocannabinol alone were carried out in 2015 within the framework of a cooperative research project focused on the ability to drive under the influence of this particular substance [9]. Togather more accurate data, an updated version of an infrared pupillograph will be used in order to increase the performance of the statistical models. This was already implemented in the single substance study mentioned. A priority objective of the study was to set up a computational model that can be easily applied during examination of drivers to preselect subjects who are under the influence of substances acting on the CNS and should be taken to the clinical examination including blood testing.

The results of this study clearly show that infrared pupillography has sufficient discriminatory power to identify subjects under the influence of drugs and/or medication in this specific setting, where $62 \%$ of all subjects had a positive blood test. The next step in our research will be to investigate a sufficiently large sample of drivers, especially single substance users and then to set up a working computational model which can be easily implemented on any computer or device. In this new situation most drivers will not be affected to this extent as compared to the subjects in our study and therefore it is possible or even likely that the current statistical model will not perform as well as in the present study. In order to cope with this new situation and to end up with a good working model, we will work with the idea of a grey area: if the model is in doubt whether a subject is affected or not, the model outputs the message: "for this subject, no identification is possible with sufficient accuracy"; and therefore such a model has the disadvantage that it does not assess all subjects. The point of the matter is that the performance of such a model is likely to end up being much better than compared to a model which is forced to assess all subjects; however, we expect to obtain more detailed information about the effects of individual substances.

\section{Conclusion}

Standardized and objective measurement methods are essential when the fitness to drive of traffic participants has to be evaluated. The statistical analysis in the present study shows that infrared pupillography has sufficient discriminatory power to identify subjects under the influence of drugs or medication, at least in this specific setting. Further studies are necessary to provide a model that can easily be implemented in police traffic checks as an instrument for preselection of drivers to be taken for further examination, especially blood testing.

\section{Corresponding address}

\section{F. Monticelli}

IFFB Gerichtsmedizin \& Forensische Neuropsychiatrie, Paris Lodron Universität Salzburg

Ignaz Harrer Str. 79, 5020 Salzburg, Austria

fabio.monticelli@sbg.ac.at

Funding. This research received no specific grant from any funding agency in the public, commercial, or not-for-profit sectors.

Open access funding provided by Paris Lodron University of Salzburg.

\section{Compliance with ethical guidelines}

Conflict of interests. W. Hitzl, T. Keller and F. Monticelli state that there are no conflicts of interest.

The accompanying manuscript does not include studies on humans or animals.

Open Access. This article is distributed under the terms of the Creative Commons Attribution 4.0 International License (http://creativecommons.org/licenses/by/ 4.0/), which permits unrestricted use, distribution, and reproduction in any medium, provided you give appropriate credit to the original author(s) and the source, provide a link to the Creative Commons license, and indicate if changes were made.

\section{References}

1. Monticelli F, Priemer F, Hitzl W, Keller T (2010) Pupil function as an indicator for being under the influence of central nervous system-acting substances from a traffic-medicine perspective. Med Sci Law 50(2):75-83

2. Monticelli F, Hitzl W, Priemer F, Preiss U, Kunz SN, Keller T (2015) The potential of infrared pupillography in routine police traffic checks. Rechtsmedizin 25:466-473

3. Lüdtke H (2005) Mess- und Analyseverfahren in der Pupillografie: Pupillografischer Schläfrigkeitstest, Pupillenlichtreflex, automatisierter SwingingFlashlight-Test und Pupillenkampimetrie. Shaker, Aachen

4. Bishop CM (2000) Neural networks for pattern recognition. Oxford University Press, Oxford

5. Dell Inc (2015) STATISTICA (data analysis software system), version 13. www.statsoft.com. Accessed 23 May 2016

6. STATISTICA neural networks, release 4.0 F, www. statsoft.com. Accessed 23 May 2016

7. Wolfram Research, Inc. (2008) Mathematica, 7th edn. Wolfram Research, Champaign

8. Kristek A (1966) Die klinische Infrarot Pupillographie. Acta Univ Palack Olomouci 24:385-391

9. Hartung $B$, Schwender $H$, Roth $E H$, Hellen $F$, Mindiashvili N, Rickert A, Ritz-Timme S, Grieser A, MonticelliF, Daldrup T(2016) The effect of cannabis on regular cannabis consumers' ability to ride a bicycle. Int J Legal Med 130(3):711-721 